\title{
Dielectric Properties of Boron Nitride-Ethylene Glycol (BN-EG) Nanofluids
}

\author{
JACEK FAL $\mathbb{1},{ }^{1,4}$ MARIAN CHOLEWA, ${ }^{2}$ MAGDALENA GIZOWSKA, ${ }^{3}$ \\ ADAM WITEK, ${ }^{3}$ and GAWEŁ ŻYŁA ${ }^{1}$
}

1.-Department of Physics and Medical Engineering, Rzeszów University of Technology, Rzeszow, Poland. 2.-Department of Biophysics, Faculty of Mathematics and Natural Sciences, University of Rzeszow, Rzeszow, Poland. 3.-Department of Nanotechnology, Institute of Ceramics and Building Materials, Warsaw, Poland. 4.-e-mail: jacekfal@prz.edu.pl

This paper presents the results of experimental investigation of the dielectric properties of ethylene glycol (EG) with various load of boron nitride (BN) nanoparticles. The nanofuids were prepared by using a two-step method on the basis of commercially available BN nanoparticles. The measurements were carried out using the Concept 80 System (NOVOCONTROL Technologies $\mathrm{GmbH} \&$ Co. KG, Montabaur, Germany) in a frequency range from $10 \mathrm{~Hz}$ to $10 \mathrm{MHz}$ and temperatures from $278.15 \mathrm{~K}$ to $328.15 \mathrm{~K}$. The frequency-dependent real $\left(\varepsilon^{\prime}\right)$ and imaginary $\left(\varepsilon^{\prime \prime}\right)$ parts of the complex permittivity $\left(\varepsilon^{*}\right)$ and the alternating current (AC) conductivity are presented. Also, the effect of temperature and mass concentrations on the dielectric properties of BN-EG nanofluids are demonstrated. The results show that the most significant increase can be achieved for $20 \mathrm{wt} . \%$ of BN nanoparticles at $283.15 \mathrm{~K}$ and $288.15 \mathrm{~K}$, that is eleven times larger than in the case of pure EG.

Key words: Dielectric properties, nanofluids, boron nitride

\section{INTRODUCTION}

Nanofluids are a new group of materials with potentially broad applications in the industry. In the last decade they have been intensively investigated by many researchers. The term was coined by Choi et al. ${ }^{1}$ to emphasize an enhancement of thermal conductivity in the suspension of nanoparticles.

A nanofluid is defined as a suspension of particles of nanometer size in a base fluid. Usually, the base fluid is distilled water, ${ }^{2-4}$ ethylene glycol, ${ }^{5-9}$ or a certain oil. ${ }^{10-14}$ Numerous papers on experimental and theoretical properties of nanofluids and their potential applications in the industry have been published so far. A broad field of applications of the nanofluids is in the systems related to heat transfer. For example, Chen et al. ${ }^{15}$ studied the possibility of using $\mathrm{TiO}_{2}$ nanofluids for cooling automobile engines. Similar studies in this field were conducted

(Received April 12, 2016; accepted September 16, 2016; published online October 7, 2016) by other researchers. ${ }^{16-19}$ In particular, Kasaeian et al., ${ }^{20}$ Kim et al., ${ }^{21}$ Leong et al., ${ }^{22}$ Mahian et al., ${ }^{23}$ and Sarsam et al. ${ }^{24}$ presented results of very extensive work on the use of nanofluids in solar energy systems. Other potential applications for nanofluids include friction reduction, ${ }^{25-27}$ magnetic sealing, ${ }^{28-31}$ biomedical applications, ${ }^{32,33}$ electronic cooling, ${ }^{34-36}$ and many others.

Such a large number of potential applications is the main reason for the great interest in nanofluids by many researchers. One of the most studied properties of nanofluids is their thermal conductivity. Many researchers reported that the addition of a small amount of nanoparticles of various ceramics, metals, or metal oxides essentially improves thermal conductivity of the base fluid. ${ }^{9,37}$

But we should also keep in mind that with increasing thermal conductivity some changes can occur in the structure of viscoelastic material, which leads to increasing viscosity of the nanofluid.

The rheological properties of nanosuspensions have been also extensively studied. It has been shown in many papers that, depending on the type 
of nanoparticles and the base fluid, some nanofluids can have a Newtonian ${ }^{38-43}$ or non-Newtonian ${ }^{44-51}$ nature. The mechanisms of these rheological properties are still not fully understood. Described in this paper, the BN-EG nanofluid has very complex rheological properties. It is a non-Newtonian shearthinning liquid, as presented in detail in Ref. 52.

Also, the optical properties of nanofluids are of major interest to scientists. ${ }^{53-55}$

The electrical conductivity and the $\mathrm{pH}$ of various nanofluids are likewise interesting for researchers. Sharifpur et al. ${ }^{5}$ investigated the combined effect of temperature, volume fraction, and energy density on some physical properties, such as the electrical conductivity, $\mathrm{pH}$, and viscosity of $\mathrm{SiO}_{2}$-EG suspensions. They performed their studies at temperatures ranging from 293.15 to $343.15 \mathrm{~K}$, volume fractions of 0 to $5 \%$, and two energy densities: $1.5 \times 10^{5} \mathrm{~kJ} / \mathrm{m}^{3}$ and $3.2 \times 10^{5} \mathrm{~kJ} / \mathrm{m}^{3}$. They reported that the electrical conductivity and $\mathrm{pH}$ levels strongly correlate with the temperature and volume fraction of nanoparticles in the base fluid. Shoghl et al. ${ }^{56}$ studied the relation between the weight concentration in the range of $0.01-1 \%$ and the electrical conductivity for fluids containing nanoparticles of $\mathrm{Al}_{2} \mathrm{O}_{3}, \mathrm{CNT}$, $\mathrm{CuO}, \mathrm{MgO}, \mathrm{TiO}_{2}$, and $\mathrm{ZnO}$. For all nanofluids, a linear increase in electrical conductivity with increasing concentrations was observed. They also confirmed an incompatibility of the Maxwell model with experimental data, as other researchers ${ }^{57-59}$ previously indicated. Mehrali et al. ${ }^{59}$ presented the results of investigation of the electrical conductivity of nitrogen-doped graphene nanofluids (NDG). They gained a stable suspension of the NDG at 0.025 wt.\% Triton X-100 aqueous solution as a base fluid. The results show that the increase of concentration of the nanoparticles in fluid causes almost linear increase in electrical conductivity up to $1814.96 \%$. Also, the temperature dependence of electrical conductivity was noticeable, but its impact was much less than the effect of concentration. Adio et al. ${ }^{60}$ performed the measurements of $\mathrm{pH}$ and electrical conductivity of the magnesium oxide-ethylene glycol nanofluids and found more than a $3000 \%$ and $40 \%$ enhancement, respectively, for electrical conductivity and $\mathrm{pH}$ levels. They have shown that both electrical conductivity and $\mathrm{pH}$ are strongly related to the temperature and volume concentrations. Also, other researchers' information and data showed similar relationships between the electrical properties, temperature, and concentration in nanofluids. ${ }^{5,61-63}$

Although there are a large number of papers about the properties of nanofluids, there is still a lack of experimental data concerning more complex electrical properties such as the electric permittivity, AC conductivity, or relaxation time. The relative permittivity and dissipation factor of a vegetable oilbased nanofluid with $\mathrm{Fe}_{3} \mathrm{O}_{4}$ nanoparticles were studied by $\mathrm{Li}$ et al. ${ }^{64}$ They reported that the dissipation factor is very similar for both pure oil and $\mathrm{Fe}_{3} \mathrm{O}_{4}$ nanofluids at frequencies above $10 \mathrm{~Hz}$. However, the relative permittivity of $\mathrm{Fe}_{3} \mathrm{O}_{4}$ nanofluids is greater than that of the oil in the measured frequency range of $10^{2}-10^{7} \mathrm{~Hz}$. Zou et al. ${ }^{65}$ also investigated insulating fluids and their dielectric properties with the addition of $\mathrm{Fe}_{3} \mathrm{O}_{4}$. The effect on size of the gold nanoparticeles (GNP) on the conductivity, permittivity, and relaxation time was studied by Abdelhalim et al. ${ }^{43}$ They reveal that GNPs have a strong dielectric dispersion depending on the particle size, and the relaxation time increases with the growth of particle size. Subramaniyan et al. ${ }^{66}$ were looking for the best base fluid to prepare the nanofluid containing $\mathrm{TiO}_{2}$ nanoparticles. They examined three different types of nanofluids with $\mathrm{TiO}_{2}$ nanoparticles suspended in water, ethylene glycol and propylene glycol at two frequencies $\left(10^{4} \mathrm{~Hz}\right.$ and $\left.10^{7} \mathrm{~Hz}\right)$ and four different temperatures $(273.15 \mathrm{~K}, 293.15 \mathrm{~K}, 373.15 \mathrm{~K}$, and $473.15 \mathrm{~K})$. Based on their results, they concluded that a higher dielectric constant was achieved for $\mathrm{TiO}_{2}$ water-based fluid. Subramaniyan et al. also noticed that the dielectric constants of this type of fluid show some changes with the variation of frequency and temperature. Dielectric studies are also carried out in the context of the application of nanofluids in medicine as a drug delivery system. Ahmed et al. ${ }^{67}$ studied nanosuspensions with magnetic nanoparticles $\left(\mathrm{Fe}_{3} \mathrm{O}_{4}\right)$ dispersed in polyethylene glycol with various amounts of anti-cancer drug (doxorubicin). They observed a decrease of conductivity with increasing amount of doxorubicin in the nanofluid. Also, slight changes in dielectric constant and dielectric loss were observed. The dielectric properties of $\mathrm{TiO}_{2}$ and $\gamma-\mathrm{Al}_{2} \mathrm{O}_{3}$ nanopowders dispersed in paraffin oil at room temperature $(298.15 \mathrm{~K})$ and frequency between $20 \mathrm{~Hz}$ and $1 \mathrm{MHz}$ were investigated by Mergos et al. ${ }^{68}$ They revealed that the inclusion of $\mathrm{Al}_{2} \mathrm{O}_{3}$ and $\mathrm{TiO}_{2}$ nanopowder does not affect significantly the real part of the dielectric constant and the loss tangent of paraffin oil. Tagmouti et al. ${ }^{69}$ carried out studies of nanofluids containing multiwalled carbon nanotubes suspended in transformer oil and their dielectric properties at constant temperature $(300 \mathrm{~K})$ in frequency range of $100 \mathrm{~Hz}$ to $1 \mathrm{MHz}$. They observed an increase of the static dielectric constant with increasing nanotube volume concentration in the base fluid, which was shown as an increase of the dielectric strength.

To the authors' knowledge, there are no publications presenting experimental results on dielectric properties of BN-EG nanofluids. Hence, this paper contributes to this field.

\section{BORON NITRIDE NANOPARTICLES}

BN nanopowder used in experiments is commercially available from Saint-Gobain Advanced Ceramics Corporation (CAS No.: 1004311-5, LOT: 


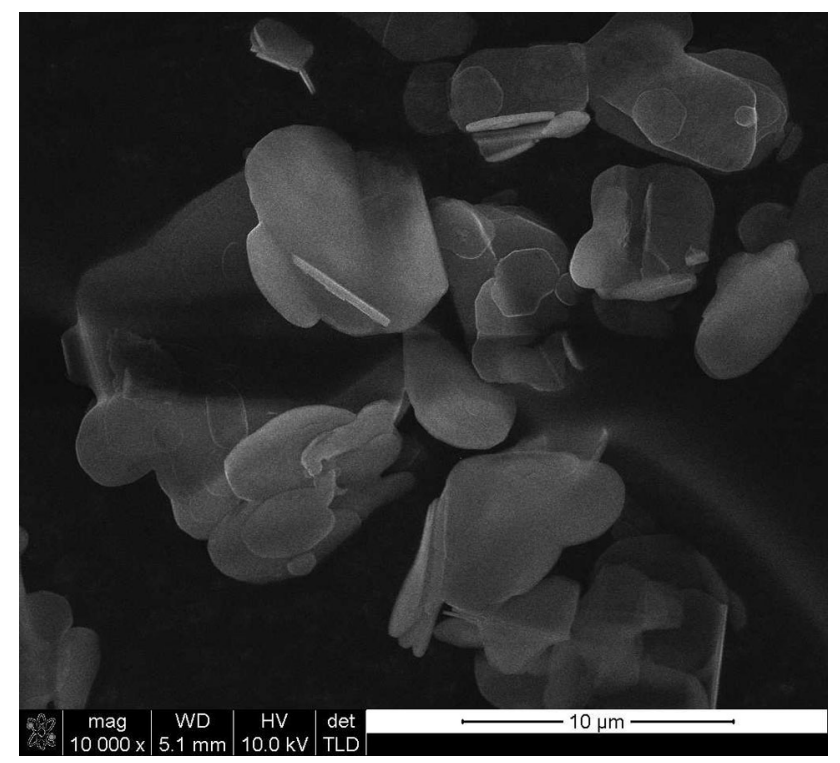

Fig 1. SEM image of dry BN nanoparticles.

94194, ID: AB134568). The nanoparticles are in plates of 1-nm size characterized by a bimodal size distribution with mean peak values of $192 \mathrm{~nm}$ and $2969 \mathrm{~nm}$, as described in Ref. 52. Figure 1 presents the scanning electron microscope (Nova NanoSEM 200; FEI, Hillsboro, OR, USA) picture of the used particles. More SEM images of nanoparticles can be found in Ref. 52.

Basic thermophysical properties (density, BET specific surface area, thermal diffusivity, and thermal conductivity) of used hexagonal crystalline form $\mathrm{BN}$ nanoplates was measured and described in Ref. 70.

\section{SAMPLE PREPARATION}

Four different samples with 5\%, 10\%, 15\%, and $20 \%$ mass concentrations of boron nitride nanoparticles in the base fluid were prepared. A sample of the pure base fluid, ethylene glycol, was also prepared. In the first step, the appropriate amount of boron nitride nanoparticles was weighed using analytic balance WAS 220/X (Radwag, Radom, Poland), and then the base fluid was added. The suspension of nanoparticles in ethylene glycol was stirred mechanically for 30 min using the Genius 3 Vortex (IKA, Staufen, Germany). The last step of sample preparation was the ultrasonic agitation in an ultrasound bath Emmi 60 HC (EMAG, Moerfelden-Walldorf, Germany) for $200 \mathrm{~min}$. All samples were prepared at the room temperature, and the measurements of dielectric properties were performed immediately after preparation of the sample.

\section{METHODS}

Dielectric properties of BN-EG nanofluids with various mass concentrations of nanoparticles were measured with the use of a BroadBand Dielectric Spectrometers Novocontrol Concept 80 System and the temperature control system Quatro Cryosystem (NOVOCONTROL Technologies GmbH \& Co. KG, Montabaur, Germany). The measurements were conducted in frequency range from $10 \mathrm{~Hz}$ to $10 \mathrm{MHz}$ in 44 steps. The temperature was controlled and stabilized from $278.15 \mathrm{~K}$ to $328.15 \mathrm{~K}$ with $5 \mathrm{~K}$ steps. The accuracy of the stabilization of temperature was $\pm 0.5 \mathrm{~K}$. The temperature was stabilized at least $15 \mathrm{~min}$ before measurements were started. The samples were placed between two round electrodes with a diameter of $40 \mathrm{~mm}$. The distance between electrode was $0.16 \mathrm{~mm}$, and it was set up using Teflon fabric.

\section{RESULTS AND DISCUSSION}

Figure 2 shows the real part of complex permittivity $\left(\varepsilon^{\prime}\right)$ of BN-EG nanofluids as a function of frequency at different temperatures and various mass concentrations of nanoparticles in the base fluid. There is a clear difference between the base fluid and nanofluids containing boron nitride nanoparicles in a low range frequency. It is clear that an increase of nanoparticle concentration in ethylene glycol causes an increase of the real part of complex permittivity of the nanofluid. This can be seen in the frequency dependence of the real part of permittivity that has two characteristic regions, and the boundary between these regions changes with temperature. At $278.15 \mathrm{~K}$ the boundary is located at about $10 \mathrm{kHz}$, but with an increase of temperature it is shifted to $80 \mathrm{kHz}$. In the first region the real part of permittivity is strongly dependent on frequency. The sharp decline in $\varepsilon^{\prime}$ may be due to the reorientation of dipoles due to external electric field, whereas, in the second region, $\varepsilon^{\prime}$ is almost constant and does not depend on frequency. A similar effect was observed by Abdelhalim et al. ${ }^{43}$ for gold nanoparticles of various diameters in the base fluid.

The dependence of imaginary part of complex permittivity $\left(\varepsilon^{\prime \prime}\right)$ on frequency for different mass concentrations of $\mathrm{BN}$ nanoparticles at various temperatures as presented in Fig. 3. In this case we also observe the growth of $\varepsilon^{\prime \prime}$ with concentration of $\mathrm{BN}$ nanoparticles in the base fluid in whole frequency range. The most significant increase in $\varepsilon^{\prime \prime}$ is between the base fluid and nanofluids containing $\mathrm{BN}$ nanoparticles. In turn, the dependence on concentration is not as significant as compared to the difference between pure ethylene glycol and nanofluid. In the double logarithmic scale the dependence of $\varepsilon^{\prime \prime}$ on frequency is almost linear in all tested frequency ranges. Only at high enough temperature we can see a slight collapse in the curves for all concentrations at a frequency below $1 \mathrm{kHz}$.

The ac conductivity $\left(\sigma_{a c}\right)$ as a function of frequency for various mass concentrations of solid nanoparticles in ethylene glycol for different temperatures is presented in Fig. 4. The addition of 

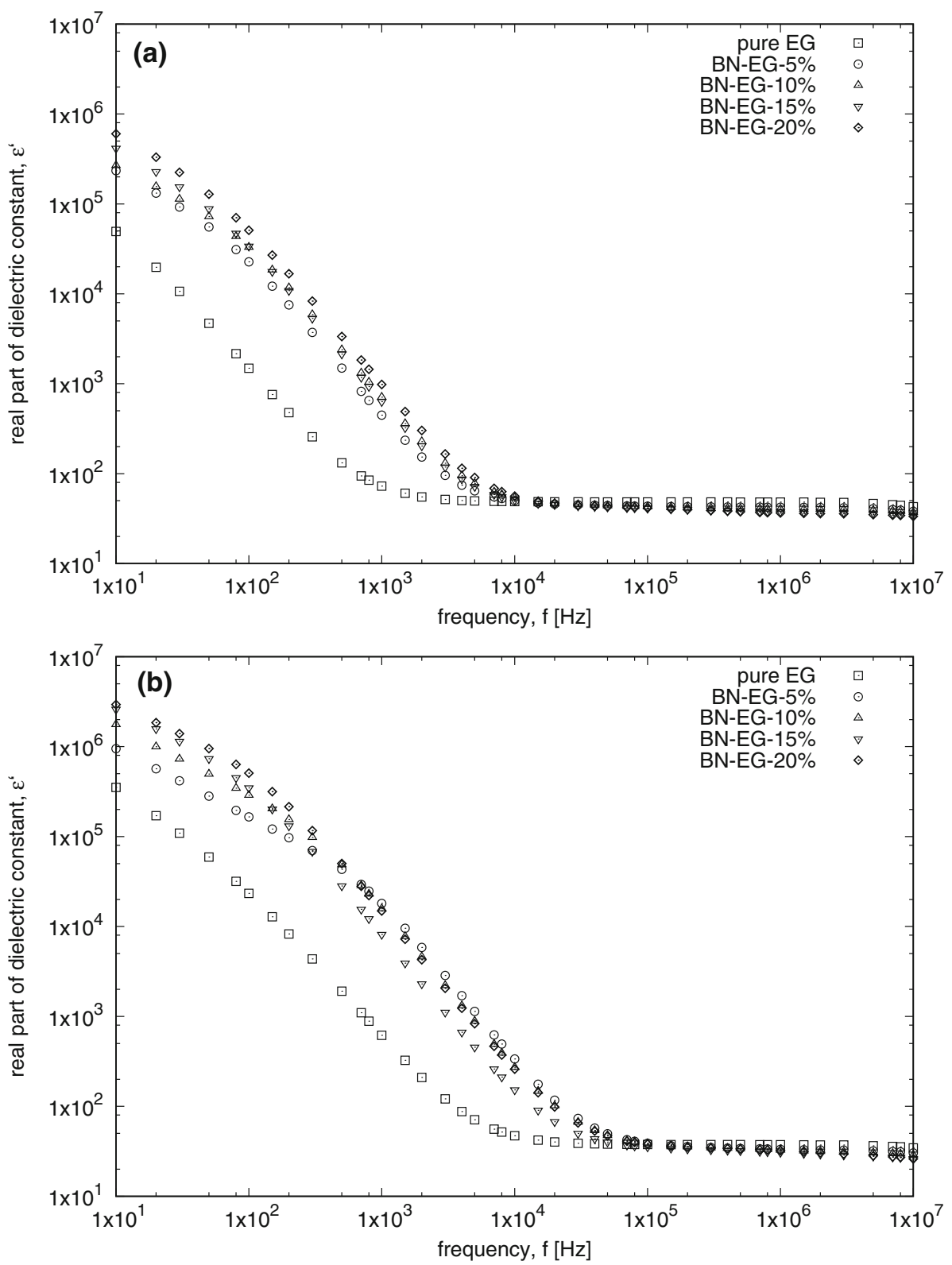

Fig 2. Frequency dependent of real part of permittivity for various mass concentrations at different temperatures: (a) $278.15 \mathrm{~K}$, (b) $323.15 \mathrm{~K}$.

boron nitride nanoparticles to the ethylene glycol leads to increase of electrical conductivity of the base fluid. This effect is visible for all frequencies, but it is most pronounced in the range of $1 \mathrm{kHz}$ to $1 \mathrm{MHz}$. In this frequency range the ac conductivity curves form a plateau. The plateaus correspond to the direct current $(\mathrm{dc})$ conductivity of nanofluids. ${ }^{71}$ In these regions of frequency, the ac conductivity is constant for all concentrations and temperatures, which is in accordance with the universal power law ${ }^{72}$ expressed as:

$$
\sigma(\omega)=\sigma_{d c}+A \omega^{n}
$$

where $\sigma_{d c}$ is the dc conductivity represented by plateau, $A$ is a numerical factor, $n$ is an exponent between 0 and 1 , and $\omega$ is the angular frequency. These parameters can be obtained by fitting the power law of Eq. 1 to our experimental data. The corresponding values of parameters $A$ and $n$ are presented in Table I.

At the lowest frequencies we observe a deviation from $\sigma_{d c}$ plateau, caused by the polarization effect of electrodes. ${ }^{72}$ The results for dc conductivity at various mass concentrations and temperatures calculated as an average of the ac conductivity over 

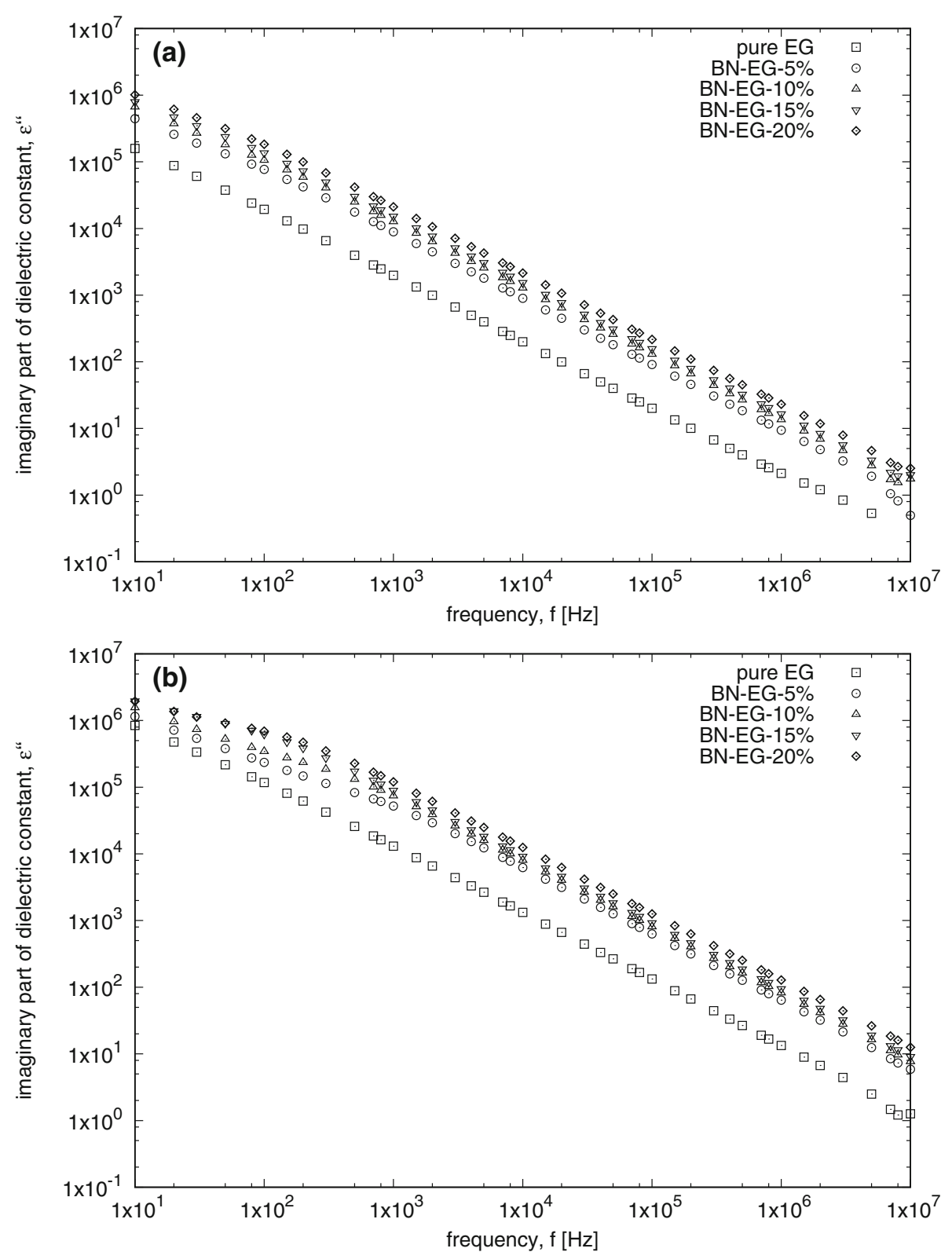

Fig 3. Frequency dependent of imaginary part of permittivity for various mass concentrations at different temperatures: (a) $278.15 \mathrm{~K}$, (b) $323.15 \mathrm{~K}$.

frequency in a frequency range between $1 \mathrm{kHz}$ and $1 \mathrm{MHz}$ are summarized in Table II and plotted in Fig. 5. According to the results presented in Fig. 5, it is obvious that the conductivity increases with the increase of temperature, and this dependence is nonlinear. Furthermore, this effect is more significant with the temperature growth. A similar effect was observed by Adio et al. ${ }^{60}$ for $\gamma-\mathrm{Al}_{2} \mathrm{O}_{3}$ glycerol nanofluids and Sharifpur ${ }^{5}$ for $\mathrm{SiO}_{2}$ ethylene glycol nanofluids. The enhancements of electrical conductivity for various mass concentrations were summarised in Table II and plotted in Fig. 6 . Analysing these results we can find that the strongest enhancement of conductivity occurs for 20 wt.\% of boron nitride nanoparticles in ethylene glycol at $283.15 \mathrm{~K}$ and $288.15 \mathrm{~K}$, and this is about $1100 \%$. In the temperature range from $278.15 \mathrm{~K}$ to $298.15 \mathrm{~K}$, the enhancement can be considered as a constant for all concentrations. Above $298.15 \mathrm{~K}$, a slight decrease in the enhancement of conductivity can be found, which is most visible for $20 \mathrm{wt} . \%$ of $\mathrm{BN}$ nanoparticles. 

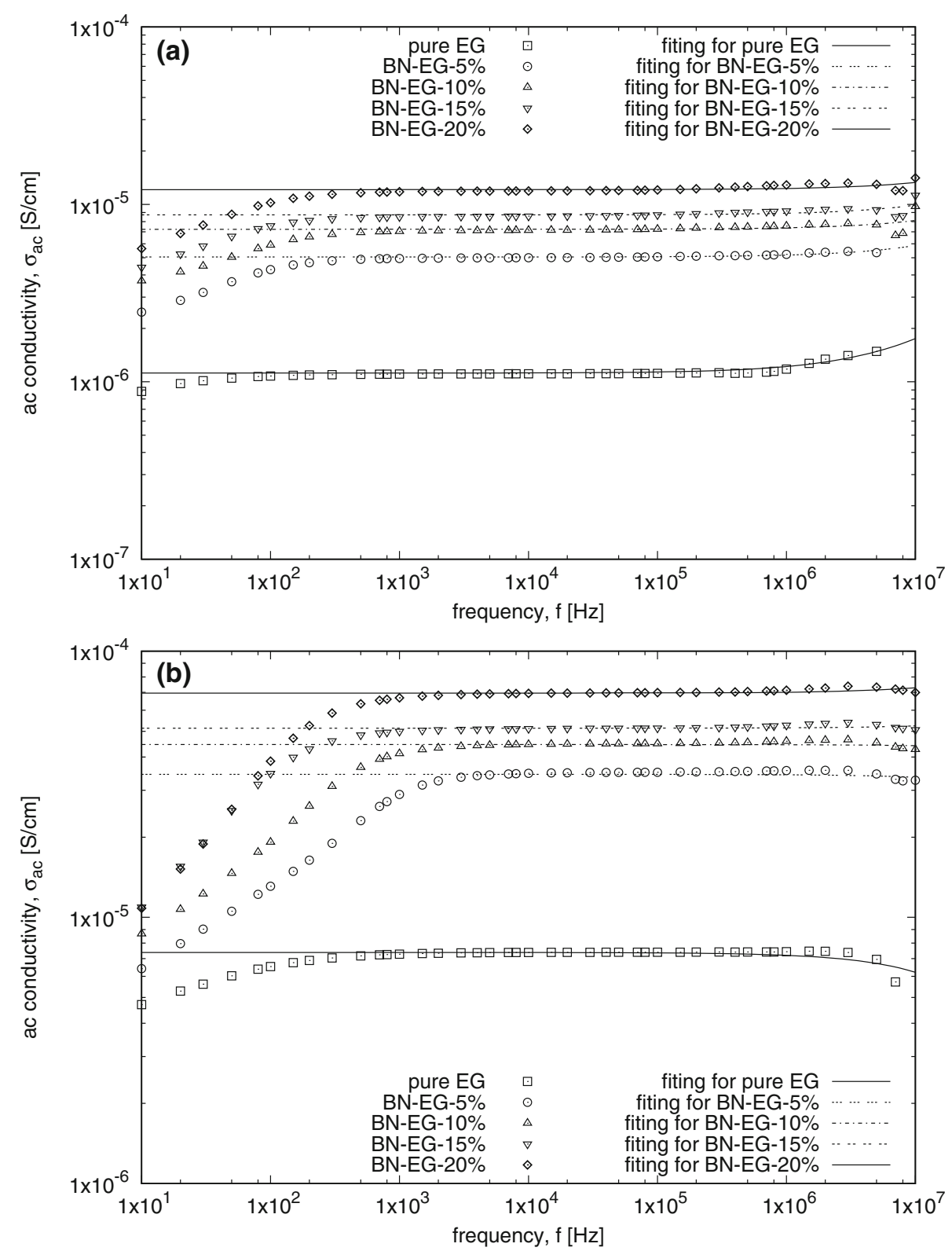

Fig 4. Frequency dependent of ac conductivity for various mass concentrations at different temperatures: (a) $278.15 \mathrm{~K}$, (b) $323.15 \mathrm{~K}$.

Table I. The value of fitting parameters $A$ and $n$ for power law

\begin{tabular}{|c|c|c|c|c|c|c|}
\hline \multirow{2}{*}{$\begin{array}{l}\varphi \\
\text { [wt.\%] }\end{array}$} & \multicolumn{3}{|c|}{$\mathbf{T}=273.15 \mathrm{~K}$} & \multicolumn{3}{|c|}{$\mathrm{T}=328.15 \mathrm{~K}$} \\
\hline & $\sigma_{d c} \times 10^{-5}[S / c m]$ & $\mathbf{A} \times \mathbf{1 0}^{-13}$ & $\mathbf{n}$ & $\sigma_{d c} \times 10^{-5}[S / \mathrm{cm}]$ & $\mathbf{A} \times \mathbf{1 0}^{-13}$ & $\mathbf{n}$ \\
\hline 0 & 0.112 & 3.30456 & 0.805494 & 0.738 & -6.02865 & 0.806230 \\
\hline 5 & 0.505 & 4.24264 & 0.806230 & 3.446 & -4.88660 & 0.802504 \\
\hline 10 & 0.724 & 4.81886 & 0.802504 & 4.458 & -2.50939 & 0.802504 \\
\hline 15 & 0.873 & 6.45073 & 0.802504 & 5.136 & 5.70199 & 0.802504 \\
\hline 20 & 1.211 & 6.51713 & 0.802504 & 6.956 & 0.18079 & 0.802504 \\
\hline
\end{tabular}


Table II. de conductivity as the average value of ac conductivity in plateau region (1-1 MHz) and their enhancement with temperature and mass concentrations

\begin{tabular}{|c|c|c|c|c|c|c|c|c|c|}
\hline \multirow[b]{2}{*}{$\mathbf{T}[\mathbf{K}]$} & \multicolumn{5}{|c|}{$\sigma_{d c} \times 10^{-5}[S / \mathrm{cm}]$} & \multicolumn{4}{|c|}{$\sigma_{\boldsymbol{d c}} / \sigma_{\boldsymbol{b f}}[-]$} \\
\hline & 0 wt. $\%$ & 5 wt. $\%$ & 10 wt. $\%$ & 15 wt.\% & 20 wt. $\%$ & 5 wt.\% & 10 wt. $\%$ & 15 wt.\% & 20 wt.\% \\
\hline 278.15 & 0.112 & 0.505 & 0.724 & 0.873 & 1.211 & 4.5 & 6.5 & 7.8 & 10.8 \\
\hline 283.15 & 0.137 & 0.640 & 0.893 & 1.087 & 1.506 & 4.7 & 6.5 & 7.9 & 11.0 \\
\hline 288.15 & 0.173 & 0.811 & 1.130 & 1.372 & 1.898 & 4.7 & 6.5 & 7.9 & 11.0 \\
\hline 293.15 & 0.214 & 1.013 & 1.405 & 1.699 & 2.347 & 4.7 & 6.6 & 7.9 & 10.9 \\
\hline 298.15 & 0.262 & 1.251 & 1.719 & 2.073 & 2.857 & 4.8 & 6.6 & 7.9 & 10.9 \\
\hline 303.15 & 0.317 & 1.530 & 2.078 & 2.496 & 3.434 & 4.8 & 6.5 & 7.9 & 10.8 \\
\hline 308.15 & 0.382 & 1.849 & 2.481 & 2.968 & 4.078 & 4.8 & 6.5 & 7.8 & 10.7 \\
\hline 313.15 & 0.457 & 2.180 & 2.932 & 3.489 & 4.789 & 4.8 & 6.4 & 7.6 & 10.5 \\
\hline 318.15 & 0.540 & 2.575 & 3.431 & 4.041 & 5.550 & 4.8 & 6.4 & 7.5 & 10.3 \\
\hline 323.15 & 0.632 & 3.006 & 3.949 & 4.621 & 6.343 & 4.8 & 6.2 & 7.3 & 10.0 \\
\hline 328.15 & 0.738 & 3.446 & 4.458 & 5.136 & 6.956 & 4.7 & 6.0 & 7.0 & 9.4 \\
\hline
\end{tabular}

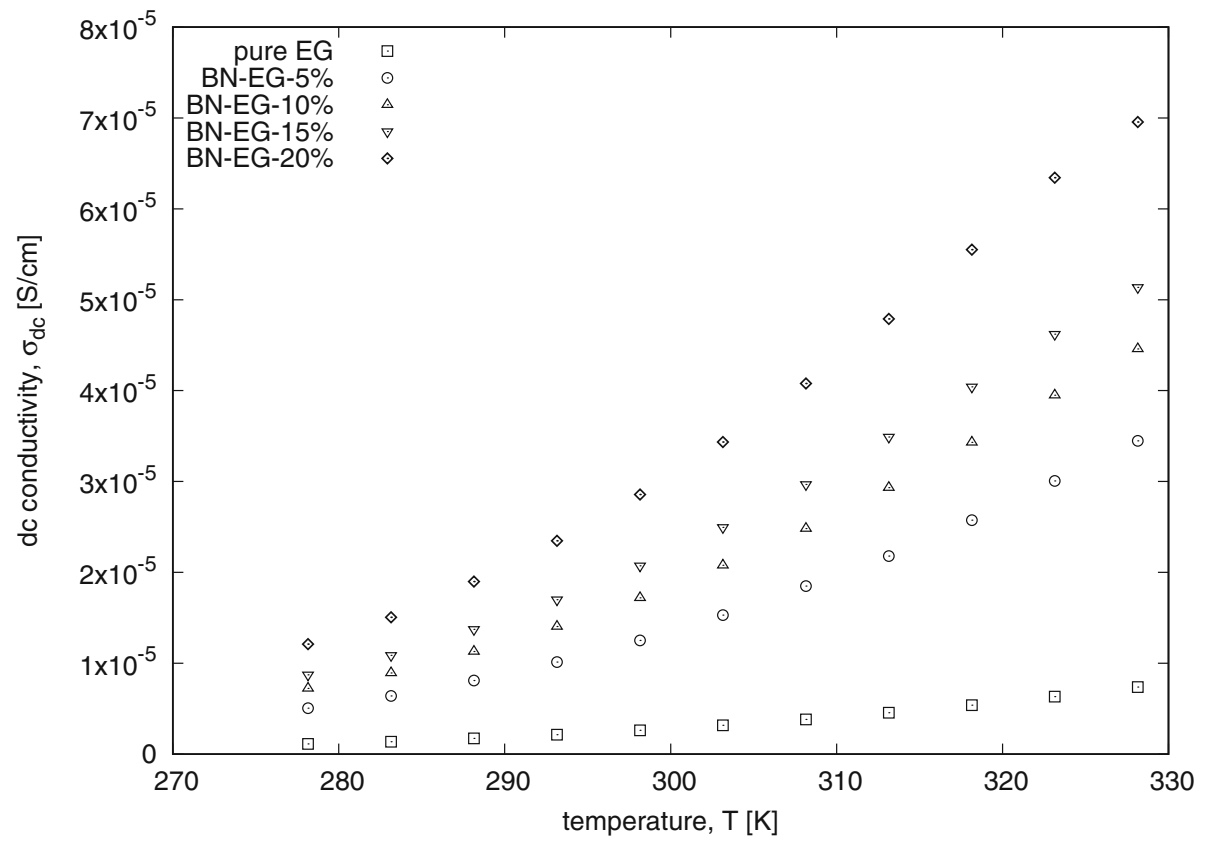

Fig 5. Temperature dependence of electrical conductivity for various mass concentrations of boron nitride nanoparticles in nanofluids as a function of temperature.

Figure 7 presents the variation of enhancement of electrical conductivity as a function of frequency and temperature. Based on the presented data it is clear that the increase of mass concentration causes an increase in the enhancement of electrical conductivity, which is close to linear dependence. In contrast to the change of mass concentrations, the change of temperature causes almost constant enhancement in the electrical conductivity. Only at high temperatures we can observe a decline in the growth of electrical conductivity enhancement. This effect is attributed to increasing mobility of nanoparticles, which accelerates sedimentation. 


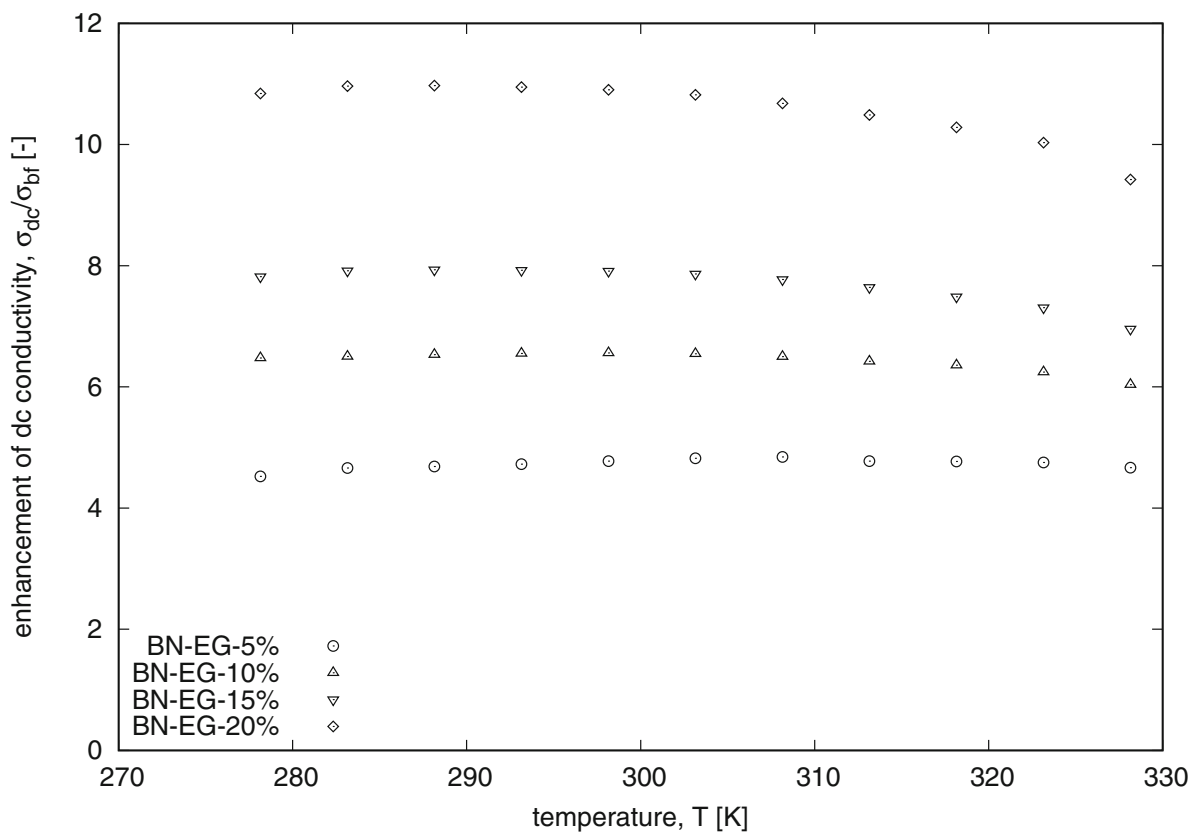

Fig 6. Temperature dependence of enhancement in dc conductivity for various mass concentrations of boron nitride nanoparticle in nanofluids as a function of temperature.

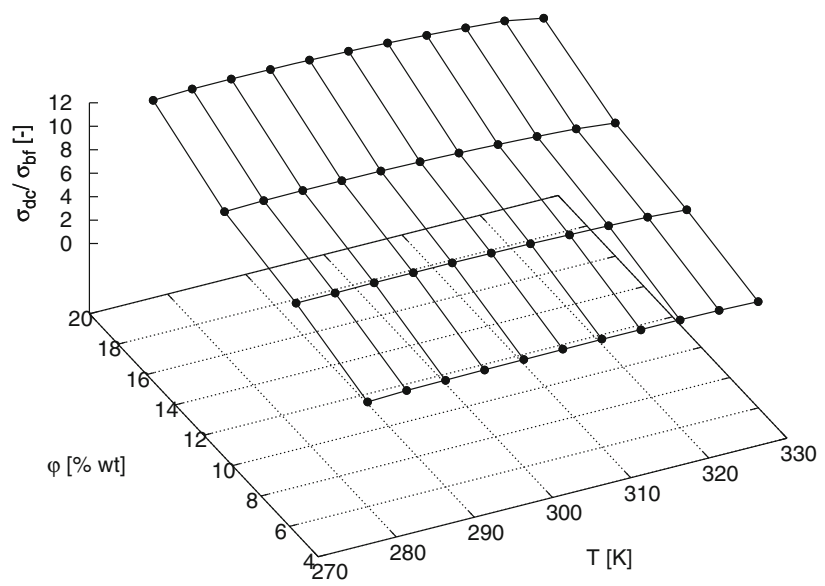

Fig 7. Enhancement in dc conductivity as function of mass concentration for various temperatures.

\section{CONCLUSION}

Dielectric properties of boron nitride nanofluids with various mass concentrations of particles at temperatures ranging from $278.15 \mathrm{~K}$ to $328.15 \mathrm{~K}$ and frequencies from $10 \mathrm{~Hz}$ to $10 \mathrm{MHz}$ were measured.

Our findings indicate that the addition of BN nanoparticles in the base fluid affect significantly the complex permittivity and the conductivity of base fluids. The increase of mass concentration of nanoparticles in the suspension causes an increase in both real and imaginary parts of complex permittivity and ac conductivity. An 11-fold increase in the dc conductivity is found for $20 \mathrm{wt} . \%$ of $\mathrm{BN}$ - nanofluid at $283.15 \mathrm{~K}$ and $288.15 \mathrm{~K}$. The influence of temperature on dielectric properties is also rather significant. An increase in temperature causes an increase in ac conductivity but the effect of temperature is not so strong as the effect of concentration.

\section{ACKNOWLEDGEMENTS}

The authors wish to thank prof. Vitalii Dugaev for proofreading the manuscript and, Dr. Andrzej Bak and Dr. Krystyna Chledowska for sharing the measuring station.

\section{OPEN ACCESS}

This article is distributed under the terms of the Creative Commons Attribution 4.0 International License (http://creativecommons.org/licenses/by/4.0/), which permits unrestricted use, distribution, and reproduction in any medium, provided you give appropriate credit to the original author(s) and the source, provide a link to the Creative Commons license, and indicate if changes were made.

\section{REFERENCES}

1. S.U.S. Choi, in Developments Applications of Non-Newtonian Flows, FED-vol. 231/MD-vol. 66, ed. D.A. Siginer and H.P. Wang (New York: ASME, 1995), pp. 99-105.

2. S. Bagheli, H.K. Fadafan, R.L. Orimi, and M. Ghaemi, Powder Technol. 274, 426 (2015).

3. M. Jarahnejad, E.B. Haghighi, M. Saleemi, N. Nikkam, R. Khodabandeh, B. Palm, M.S. Toprak, and M. Muhammed, Rheol. Acta 54(5), 411 (2015).

4. L. Zhu, M.L. Chen, J.G. Choi, C.Y. Park, S.C. Lee, D.S. Hong, J.G. Lee, and W.C. Oh et al., Asian J. Chem. 24(2), 908 (2012).

5. M. Sharifpur, S. Adio, and J. Meyer, in International Conference on Heat Transfer, Fluid Mechanics and Thermodynamics (South Africa: Kruger National Park, 2015), pp. 199-204. 
6. S.A. Adio, M. Sharifpur, and J.P. Meyer, Bull. Mater. Sci. 38(5), 1345 (2015).

7. H. Xie, W. Yu, and W. Chen, J. Exp. Nanosci. 5(5), 463 (2010).

8. D. Cabaleiro, M.J. Pastoriza-Gallego, C. Gracia-Fernández, M.M. Piñeiro, and L. Lugo, Nanoscale Res. Lett. 8(1), 1 (2013).

9. W. Yu, H.Q. Xie, Y. Li, and L.F. Chen, in ASME 2009 7th International Conference on Nanochannels, Microchannels, and Minichannels (American Society of Mechanical Engineers, 2009), pp. 901-905.

10. D.H. Fontes, G. Ribatski, and E.P. Bandarra, Filho. Diam. Relat. Mater. 58, 115 (2015).

11. J. Miao, M. Dong, and L.P. Shen, in Condition Monitoring and Diagnosis (CMD), 2012 International Conference on (IEEE, 2012), pp. 1126-1129.

12. V. Segal, A. Hjortsberg, A. Rabinovich, D. Nattrass, and K. Raj, in Conference Record of the 1998 IEEE International Symposium on Electrical Insulation, 1998, vol. 2 (IEEE, 1998), pp. 619-622.

13. H. Jin, Dielectric Strength and Thermal Conductivity of Mineral Oil based Nanofluids (Delft University of Technology, Delft, 2015).

14. X. Li, C. Zou, L. Zhou, and A. Qi, Int. J. Heat Mass Transf. 97, 631 (2016).

15. J.M. Chen, X.Y. Sun, G.J. Leng, and J.H. Feng, Key Eng. Mater. 645, 444-448 (2015).

16. V. Bhimani, P. Ratho, and A. Sorathiya, Int. J. Emerg. Technol. Adv. Eng. 3, 295 (2013).

17. D. Chavan and A.T. Pise, J. Therm. Sci. Eng. Appl. 6(2), 021010 (2014).

18. K. Leong, R. Saidur, S. Kazi, and A. Mamun, Appl. Therm. Eng. 30(17), 2685 (2010).

19. S. Peyghambarzadeh, S. Hashemabadi, S. Hoseini, and M.S. Jamnani, Int. Commun. Heat Mass Transf. 38(9), 1283 (2011).

20. A. Kasaeian, A.T. Eshghi, and M. Sameti, Renew. Sustain. Energy Rev. 43, 584 (2015).

21. P.J. Kim, S.H. Rhi, K.B. Lee, H.C. Hwang, J.S. Lee, J.C. Jang, W.H. Lee, and K.W. Lee, J. Electron. Mater. 43(6), 1613 (2014).

22. K. Leong, H.C. Ong, N. Amer, M. Norazrina, M. Risby, and K.K. Ahmad, Renew. Sustain. Energy Rev. 53, 1092 (2016).

23. O. Mahian, A. Kianifar, S.A. Kalogirou, I. Pop, and S. Wongwises, Int. J. Heat Mass Transf. 57(2), 582 (2013).

24. W.S. Sarsam, S. Kazi, and A. Badarudin, Sol. Energy 122, 1245 (2015)

25. M. Azaditalab, A. Houshmand, and A. Sedaghat, Tribol. Int. 94, 329 (2016).

26. B. Shen, A.J. Shih, and S.C. Tung, Tribol. Trans. 51(6), 730 (2008).

27. J. Zhou, Z. Wu, Z. Zhang, W. Liu, and Q. Xue, Tribol. Lett. 8(4), 213 (2000).

28. I. Borbáth, Z. Kacsó, L. Dávid, I. Potencz, D. Bica, O. Marinică, and L. Vékás, Convergence of Micro- and Nanoengineering (Bucharest: Romanian Academy Publishing House, 2006), pp. 200-210. http://www.roseal.eu/kep/MNFseals_ lucrareROMJIST.pdf.

29. T. Borbáth, D. Bica, I. Potencz, I. Borbáth, T. Boros, and L. Vékás, Int. J. Fluid Mach. Syst. 4(1), 67 (2011).

30. D.K. Devendiran and V.A. Amirtham, Renew. Sustain. Energy Rev. 60, 21 (2016).

31. Y. Mitamura, S. Arioka, D. Sakota, K. Sekine, and M. Azegami, J. Phys. Condens. Matter 20(20), 204145 (2008).

32. L. Zhang, Y. Jiang, Y. Ding, M. Povey, and D. York, J. Nanopart. Res. 9(3), 479 (2007).

33. A. Panacek, L. Kvitek, R. Prucek, M. Kolar, R. Vecerova, N. Pizurova, V.K. Sharma, T. Nevecna, and R. Zboril, J. Phys. Chem. B 110(33), 16248 (2006).

34. S.S. Chougule and S. Sahu, J. Electron. Packag. 137(2), 021004 (2015).
35. P. Selvakumar and S. Suresh, Nanotechnology 2012: Electronics, Devices, Fabrication, MEMS, Fluidics and Computational, vol. 2 (2012), pp. 133-136.

36. M. Sohel, R. Saidur, S. Khaleduzzaman, and T.A. Ibrahim, Int. Commun. Heat Mass Transf. 65, 89 (2015).

37. J.A. Eastman, S. Choi, S. Li, W. Yu, and L. Thompson, Appl. Phys. Lett. 78(6), 718 (2001).

38. A. Mariano, M.J. Pastoriza-Gallego, L. Lugo, L. Mussari, and M.M. Pineiro, Int. J. Heat Mass Transf. 85, 54 (2015).

39. M. Pastoriza-Gallego, L. Lugo, D. Cabaleiro, J. Legido, and M. Pineiro, J. Chem. Thermodyn. 73, 23 (2014).

40. M. Hemmat Esfe, S. Saedodin, A. Asadi, and A. Karimipour, J. Therm. Anal. Calorim. 120(2), 1145-1149 (2015).

41. P.K. Namburu, D.P. Kulkarni, D. Misra, and D.K. Das, Exp. Therm. Fluid Sci. 32(2), 397 (2007).

42. G. Żyła, Int. J. Heat Mass Transf. 92, 751 (2016).

43. M.A.K. Abdelhalim, M.M. Mady, and M.M. Ghannam, $L i$ pids Health Dis. 10(1), 1 (2011).

44. M. Pastoriza-Gallego, L. Lugo, J. Legido, and M. Piñeiro, Nanoscale Res. Lett. 6(1), 560 (2011).

45. W.J. Tseng and K.C. Lin, Mater. Sci. Eng. A 355(1-2), 186 (2003).

46. D. Cabaleiro, M.J. Pastoriza-Gallego, C. Gracia-Fernández, M.M. Pineiro, and L. Lugo, Nanoscale Res. Lett. 8(1), 1 (2013).

47. A. Mariano, M.J. Pastoriza-Gallego, L. Lugo, A. Camacho, S. Canzonieri, and M.M. Pineiro, Fluid Phase Equilib. 337, 119 (2013).

48. X. Li, C. Zou, T. Wang, and X. Lei, Int. J. Heat Mass Transf. 84, 925 (2015).

49. M. Hojjat, S. Etemad, R. Bagheri, and J. Thibault, Int. Commun. Heat Mass Transf. 38(2), 144 (2011).

50. G. Żyła, J. Fal, M. Gizowska, A. Witek, and M. Cholewa, Acta Phys. Pol. A 128(2), 240 (2015).

51. G. Żyła and J. Fal, Thermochim. Acta 637, 11 (2016).

52. G. Żyła, A. Witek, and M. Gizowska, J. Appl. Phys. 117(1), 014302 (2015).

53. S. Brojabasi, T. Muthukumaran, and J. Laskar, J. Philip, Opt. Commun. 336, 278 (2015).

54. D. Song, Y. Wang, D. Jing, and J. Geng, Int. J. Heat Mass Transf. 96, 430 (2016).

55. M. Sajid, Z. Said, R. Saidur, F. Adikan, M. Sabri, and N. Rahim, Int. Commun. Heat Mass Transf. 50, 108 (2014).

56. S.N. Shoghl, J. Jamali, and M.K. Moraveji, Exp. Therm. Fluid Sci. 74, 339 (2016).

57. S. Ganguly, S. Sikdar, and S. Basu, Powder Technol. 196(3), 326 (2009).

58. A.A. Minea and R.S. Luciu, Microfluid. Nanofluid. 13(6), 977 (2012)

59. M. Mehrali, E. Sadeghinezhad, M.M. Rashidi, A.R. Akhiani, S.T. Latibari, M. Mehrali, and H.S.C. Metselaar, J. Nanopart. Res. 17(6), 1 (2015).

60. S.A. Adio, M. Sharifpur, and J.P. Meyer, in Proceedings of the 15th International Heat Transfer Conference, Kyoto, paper IHTC15-8604 (2014), pp. 11-15.

61. K.K. Sarojini, S.V. Manoj, P.K. Singh, T. Pradeep, and S.K. Das, Colloids Surf. A Physicochem. Eng. Asp. 417, 39 (2013).

62. E.K. Goharshadi and H. Azizi-Toupkanloo, Powder Technol. 237, 97 (2013).

63. M. Hadadian, E.K. Goharshadi, and A. Youssefi, J. Nanopart. Res. 16(12), 1 (2014).

64. J. Li, Z. Zhang, P. Zou, S. Grzybowski, and M. Zahn, IEEE Electr. Insul. Mag. 28(5), 43 (2012).

65. P. Zou, J. Li, C.X. Sun, Z.T. Zhang, and R.J. Liao, Mod. Phys. Lett. B 25(25), 2021 (2011).

66. A. Subramaniyan, L.P. Sukumaran, and R. Ilangovan, J. Taibah Univ. Sci. 10(3), 403 (2015). 
67. R. Ahmed, M. Fadel, M.S. Hanafy, and M.A. Ibrahim, IOSR J. Appl. Phys. 6, 38-46 (2014).

68. J.A. Mergos, M.D. Athanassopoulou, T.G. Argyropoulos, and C.T. Dervos, IEEE Trans. Dielectr. Electr. Insul. 19(5), 1502 (2012).

69. S. Tagmouti, S. Bouzit, L. Costa, M. Graça, and A. Outzourhit, Spectrosc. Lett. 48(10), 761 (2015).
70. G. Żyła, J. Fal, J. Traciak, M. Gizowska, and K. Perkowski, Mater. Chem. Phys. 180, 250 (2016).

71. M. Chapartegui, N. Markaide, S. Florez, C. Elizetxea, M. Fernandez, and A. Santamaria, Polym. Eng. Sci. 52(3), 663 (2012).

72. D.K. Pradhan, R. Choudhary, and B. Samantaray, Int. J. Electrochem. Sci. 3, 597 (2008). 